\title{
Histopathological aspects of Bovine Enzootic Hematuria in Brazil ${ }^{1}$
}

\author{
Paulo Vargas Peixoto ${ }^{2 *}$, Ticiana do Nascimento França ${ }^{3}$, Claudio S.L.Barros ${ }^{4}$ and \\ Carlos Hubinger Tokarnia ${ }^{5}$
}

\begin{abstract}
Peixoto P.V., França, T.N., Barros, C.S.L. \& Tokarnia, C.H. 2003. [Histopathological aspects of Bovine Enzootic Haematuria in Brazil.] Pesquisa Veterinaria Brasileira 23(3):65-81. Depto Nutrição Animal e Pastagem, Instituto de Zootecnia, UFRRJ, Km 47, Seropédica, Rio de Janeiro 23835-000, Brazil. E-mail: peixotop@ufrrj.br

The bladder lesions of 59 cattle, from the States of Rio de Janeiro, São Paulo, Minas Gerais, Espírito Santo, Rio Grande do Sul, Santa Catarina, Paraná and Amazon, affected by Bovine Enzootic Haematuria (BEH), were studied histologically. The objective of this study was to describe and reclassify neoplastic and non-neoplastic alterations not yet reported, according to the more complete current nomenclature used in human medicine. There was an almost complete identity with alterations observed in the bladder of man. Due to the occurrence of two or more neoplasms in the same animal, differences in the methodology and in the concept of classification, a more precise comparison was not possible. Coexistence of different types of epithelial and/or mesenchymal tumour growth was frequently seen. Rare neoplasms or differentiations not previously described were found in the bladder of some animals affected by BEH. These were trabecular carcinoma with Paneth cells differentiation, mesonephroid adenoma, mesonephroid adenocarcinoma, "signet ring" cell carcinoma, plasmocytoid carcinoma, chromophobe cell carcinoma and nested type of transitional cell carcinoma. Haemangiosarcomas originating from haemangiomas were also observed. This study also revealed the occurrence of many tumors with anaplasia and pronounced infiltrative features, but which did not metastasize. The elucidation of the cause of this "barrier against metastases" and its relationship with chemical carcinogenesis induced by the ptaquiloside, the active principle of bracken fern (Pteridium aquilinum), could be of interest to future research on the control of neoplasia in man and animals.
\end{abstract}

INDEX TERMS: Histopathology, Bovine Enzootic Hematuria, bladder tumors, Pteridium aquilinum, Brazil.

RESUMO.- [Aspectos histopatológicos da Hematúria Enzoótica Bovina no Brasil.] Com o objetivo de descrever alterações neoplásicas e não-neoplásicas ainda não relatadas e, paralelamente, reclassificá-las de acordo com nomenclatu-

\footnotetext{
${ }^{1}$ Accepted for publication on February 5, 2003.

${ }^{2}$ Depto Nutrição Animal e Pastagem, Instituto de Zootecnia, Universidade Federal Rural do Rio de Janeiro (UFRRJ), 23835-000 Seropédica, RJ, Brasil. *Autor para correspondência. E-mail: peixotop@ufrrj.br

${ }^{3}$ Disciplina de Anatomia Patológica, Curso de Medicina Veterinária da Universidade Estácio de Sá, Estrada Boca do Mato 850, Vargem Pequena, Rio de Janeiro 22783-320, Brasil. E-mail: ticiana@uol.com.br

${ }^{4}$ Depto Patologia, Universidade Federal de Santa Maria, 97105-900 Santa Maria, RS, Brasil. E-mail: claudioslbarros@uol.com.br

${ }^{5}$ Depto Nutrição Animal e Pastagem, Instituto de Zootecnia, UFRRJ. Email: tokarnia@ufrrj.br
}

ra mais completa e atual utilizada em medicina humana, foram estudadas, histologicamente, lesões da bexiga de 59 bovinos com Hematúria Enzoótica (HEB), oriundos dos Estados do Rio de Janeiro, São Paulo, Minas Gerais, Espírito Santo, Rio Grande do Sul, Santa Catarina, Paraná e Amazonas.Verificou-se, em termos qualitativos, quase uma perfeita identidade com as lesões de bexiga observadas em seres humanos. Comparações mais exatas com relação à frequiência dessas alterações ficaram prejudicadas, dadas a ocorrência de duas ou mais neoplasias em um mesmo animal e as diferenças da metodologia empregada ou do conceito de classificação. Coexistência entre neoplasias diversas, epiteliais e/ ou mesenquimais, foi vista com freqüência. Neoplasias ou diferenciações raras, ainda não descritas na bexiga de bovinos, como carcinoma trabecular com diferenciação em células de Paneth, adenoma e adenocarcinoma mesonefróides, 
carcinoma "signet ring" (anel de sinete), carcinoma plasmocitóide, carcinoma de células cromófobas e carcinoma transicional tipo ninhado foram observadas na bexiga de alguns animais com HEB. Foram verificados hemangiossarcomas proliferando a partir de hemangiomas. $O$ estudo revelou, ainda, a ocorrência de diversos tumores com anaplasia e carácter infiltrativo acentuados, incapazes, porém, de metastizarem. O esclarecimento da(s) causa(s) dessa "barreira à metástase" e suas relações com a carcinogênese química induzida pelo ptaquilosídeo, o princípio ativo de Pteridium aquilinum, talvez possa ser de interesse em futuros estudos que visem combater o câncer no homem e nos animais.

TERMOS DE INDEXAÇÃO: Histopatologia, Hematúria enzoótica bovina, tumores de bexiga, Pteridium aquilinum, Brasil.

\section{INTRODUCTION}

Pteridium aquilinum (L.) Kuhn, a poisonous plant known as bracken fern, has been registered in almost all continents; it has a wide distribution in Brazil. This plant causes different pathological symptoms, mainly because it contains two different toxic principles: one radiomimetic carcinogenic compound, the norsesquiterpene ptaquiloside (Hirono et al. 1984) and a thiaminase type I (Evans et al. 1963, Evans 1976).

Depending on the period during which the plant is eaten and on the amount ingested (Tokarnia et al. 2000), the radiomimetic principle is responsible for three different clinicalpathological pictures, observed mainly in cattle: hemorrhagic diathesis (HD) (Sippel 1952, Evans et al. 1954, Naftalin \& Cushnie 1954), bovine enzootic hematuria (BEH) (Heeschen 1959, Rosenberger \& Heeschen 1960, Rosenberger 1965, Döbereiner et al. 1967) and carcinomas of the upper digestive tract (CUDT) (Döbereiner et al. 1967, Tokarnia et al. 1969, Pirie 1973).

The nature of the bladder tumors, associated with the ingestion of $P$. aquilinum, is quite peculiar. Epithelial tumors, as well as mesenchymal tumors have been described, beside the strange capacity to induce different neoplasms in a same animal (Tokarnia et al. 2000).

Histological examination of new cases of bovine enzootic hematuria revealed several undescribed bladder neoplasms. The microscopic reexamination and reclassification of cases originating from previous publications (Döbereiner et al. 1967, Tokarnia et al. 1969) was also performed to standardize and update the diagnoses according to the most recent nomenclature.

The aim of this paper is to characterize and to describe histologically neoplastic and non-neoplastic bladder lesions of cattle, not yet reported in scientific papers on BEH. At the same time, previously described lesions have been reclassified adopting the more complete nomenclature currently used in human medicine. It is hoped that this will call attention to improvements in veterinary pathology.

\section{MATERIAL AND METHODS}

Local. The study was developed in the Section of Pathology, of the Convênio Embrapa/Universidade Federal of Rio de Janeiro (UFRRJ), located at $\mathrm{Km} \mathrm{47,} \mathrm{Seropédica,} \mathrm{Rio} \mathrm{de} \mathrm{Janeiro.}$

Appraised cases. From 59 histologically-examined cases, originating from Rio de Janeiro, São Paulo, Minas Gerais, Paraná, Amazônia, Espírito Santo, 15 were seen during the routine work of the Section of Pathological Anatomy (Embrapa/UFRRJ), 8 cases during routine work of the Veterinary Pathology Section of the Federal University of Santa Maria (UFSM/Rio Grande do Sul), 17 cases, part of which were processed at UFSM/RS and another part at Embrapa/ UFRRJ originating from São Paulo, and 19 belonging to the studies published by Döbereiner et al. (1967) and by Tokarnia et al. (1969) (originating from Espírito Santo, Minas Gerais, Rio de Janeiro and Santa Catarina).

Material. Most of the analyzed material was stored in paraffin blocks or already prepared tissues sections. Some old tissue sections were discolored with acetic acid and stained again with hematoxilineosin (HE). The materials in paraffin blocks were cut 5 micrometers thick, stained with HE and submitted to histopathological examination. In some cases special colorations were made by PAS (Schiff's reagent), toluidine blue or Masson's trichrome stain for connective tissue. The tissue sections were examined by optical microscopy. Animals submitted to us for post-mortem examination, had their organs collected immediately after death. The fragments for histopathological study were fixed in $10 \%$ formalin and processed by the usual methods.

Methodology used for classification and counting of the tumors. As there is no recent and complete histological classification of the bladder tumors of domestic animals in the literature, this study was based on human medical classifications used by the Armed Forces Institute of Pathology of the United States of America (AFIP), elaborated by Murphy et al. (1994) and on the nomenclature of the book Ackerman's Surgical Pathology, used by Ordónez \& Rosai (1996). These were compared with the International Histological Classification of Tumors of Domestic Animals of the World Health Organization (WHO), elaborated for bladder tumors by Pamukçu (1974). Some animals had more than one tumor. Neoplastic processes, visualized separately in a section, without physical proximity, were classified separately. When the tumors occupied small areas and were of different morphology, distinguishing themselves from most of the neoplasm, these areas were considered as differentiations and not as separate tumors.

\section{RESULTS}

The changes found in the bladder of the animals were divided into neoplastic and non-neoplastic; the last ones were subdivided into inflammatory, hyperplastic and metaplastic. The coexistence among them was almost constant, and the frequent simultaneous occurrence of several of them was observed in the same bladder, as can be seen in Figures 1-9 and Tables 1-5. Due to these miscellaneous lesions, it was frequently difficult or impossible to establish which was the main alteration and the chronological order of emergence of these lesions, as the tumors and the metaplastic alterations seemed to arise, at the same time, on several sites of the mucous membrane. However, only a few bladder fragments were available from many animals. In some cases there was a clear "differentiation" of one type of tissue into another at the same location. For instance, foci of hyperplastic urothelium with "intestinal" or mesonephroid changes differentiated at the base into carcinoma "in situ" or into "intestinal" adenocarcinoma, sometimes already with a clear infiltrative tendency. In other 

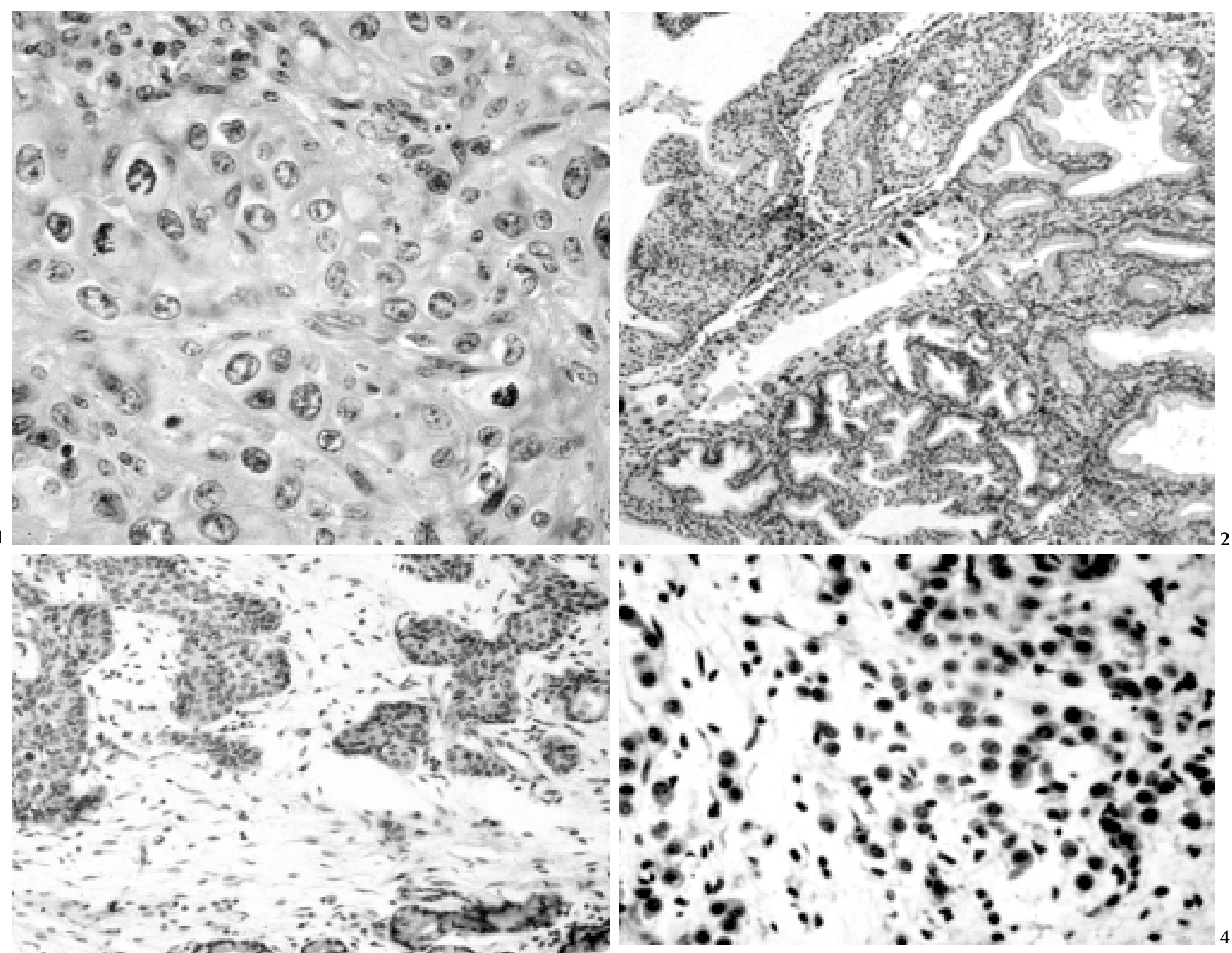

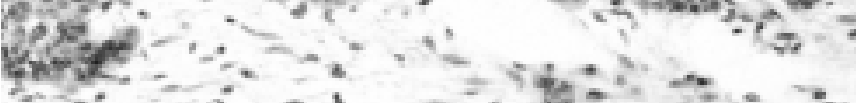

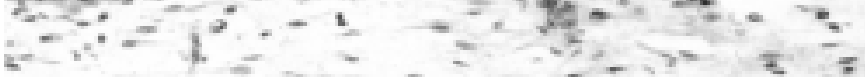

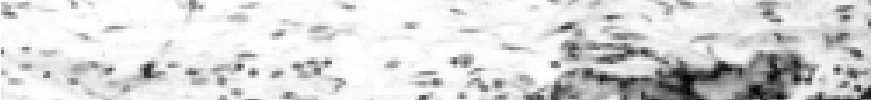

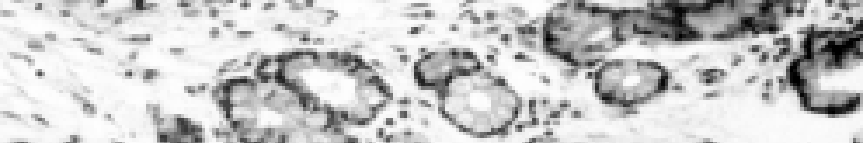

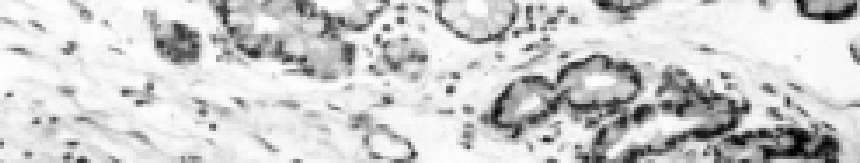

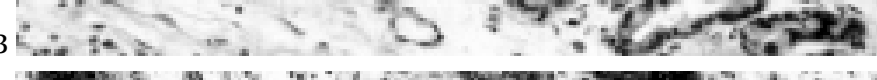

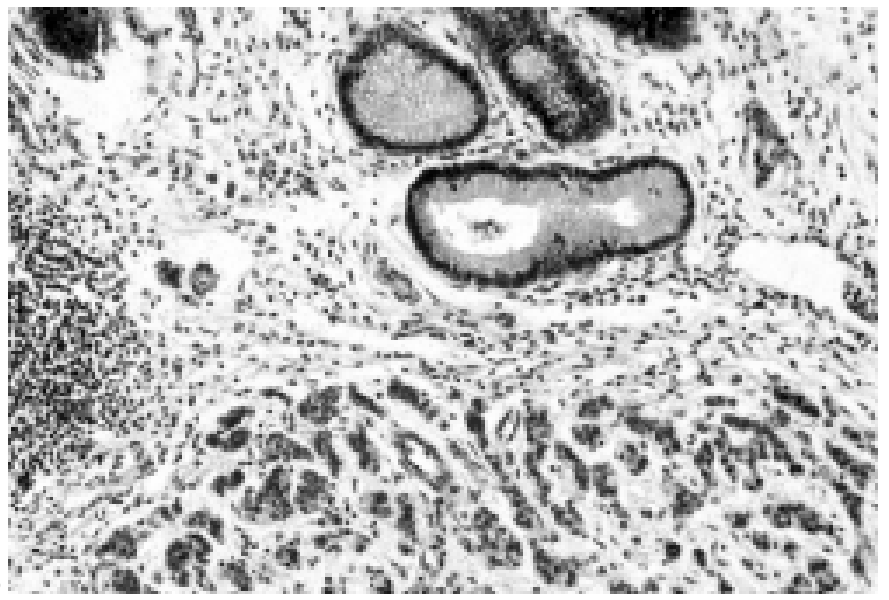

Fig. 1. Histopathological aspects of Bovine Enzootic Hematuria (BEH) in Brazil. Poorly differentiated carcinoma (Bov. 4864, 24581). HE, obj. 40.

Fig. 2. Carcinoma "in situ" with bizarre cells (invaginated), adenocarcinoma with intestinal differentiation and moderate dysplasia in BEH (Bov. 4862, 24496). HE, obj. 10.

Fig. 3. Transitional cell carcinoma moderate-grade (there are other areas with more anaplastic cells) with myxoid stroma; on the lower part, an adenocarcinoma with intestinal differentiation in BEH (Bov. 4862, 24496). HE, obj. 16.

Fig. 4. Plasmacytoid carcinoma in BEH (Bov. 4862, 24496). HE, obj. 40.

Fig. 5. Trabecular carcinoma (down) and Cystitis glandularis (up), with focal (left) and diffuse interstitial lymphocytic infiltration in BEH (Bov. 4862, 24496). HE, obj. 20. 

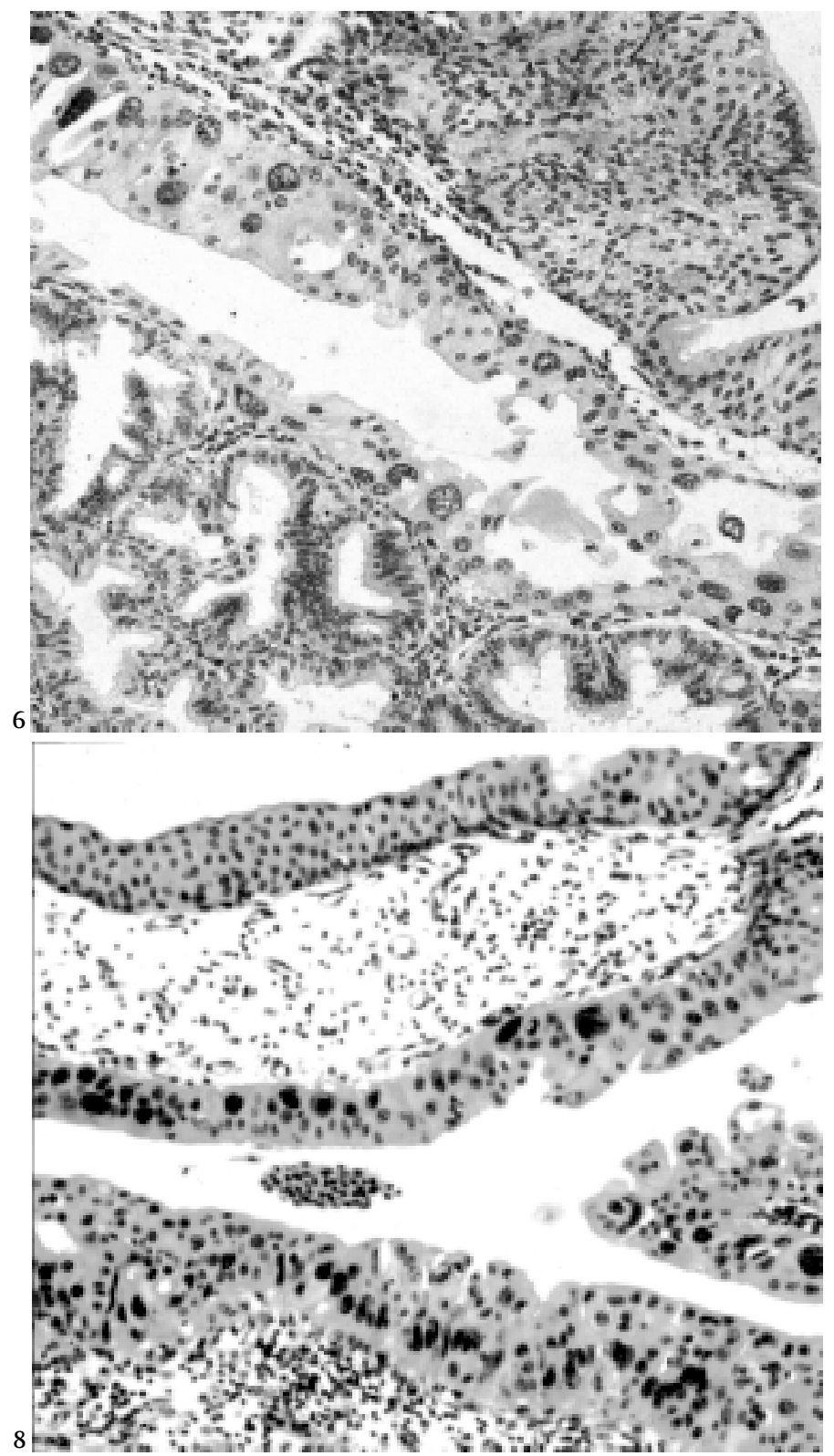

Fig. 6. Histopathological aspects of Bovine Enzootic Hematuria (BEH) in Brazil. Carcinoma "in situ" with bizarre cells (invaginated), adenocarcinoma with intestinal differentiation and moderate urothelial dysplasia in (Bov. 4862, 24496). HE, obj. 20.

Fig. 8. Carcinoma "in situ" with polypoid proliferation, myxoid stroma and diffuse lymphocytic infiltration in BEH (Bov. 4862, 24496). HE, obj. 20.

animals, evident hyperplastic, metaplastic and/or neoplastic cellular proliferation, at areas distant from one to another was verified, which characterizes multicentric lesions with different types of differentiation. This was also observed in mesenchymal tissues, since part of the hemangiomas and hemangiosarcomas seemed to be related to or originated from focal or multifocal proliferation of small vessels morphologically of normal aspect. In fact, this last alteration was verified in many of the

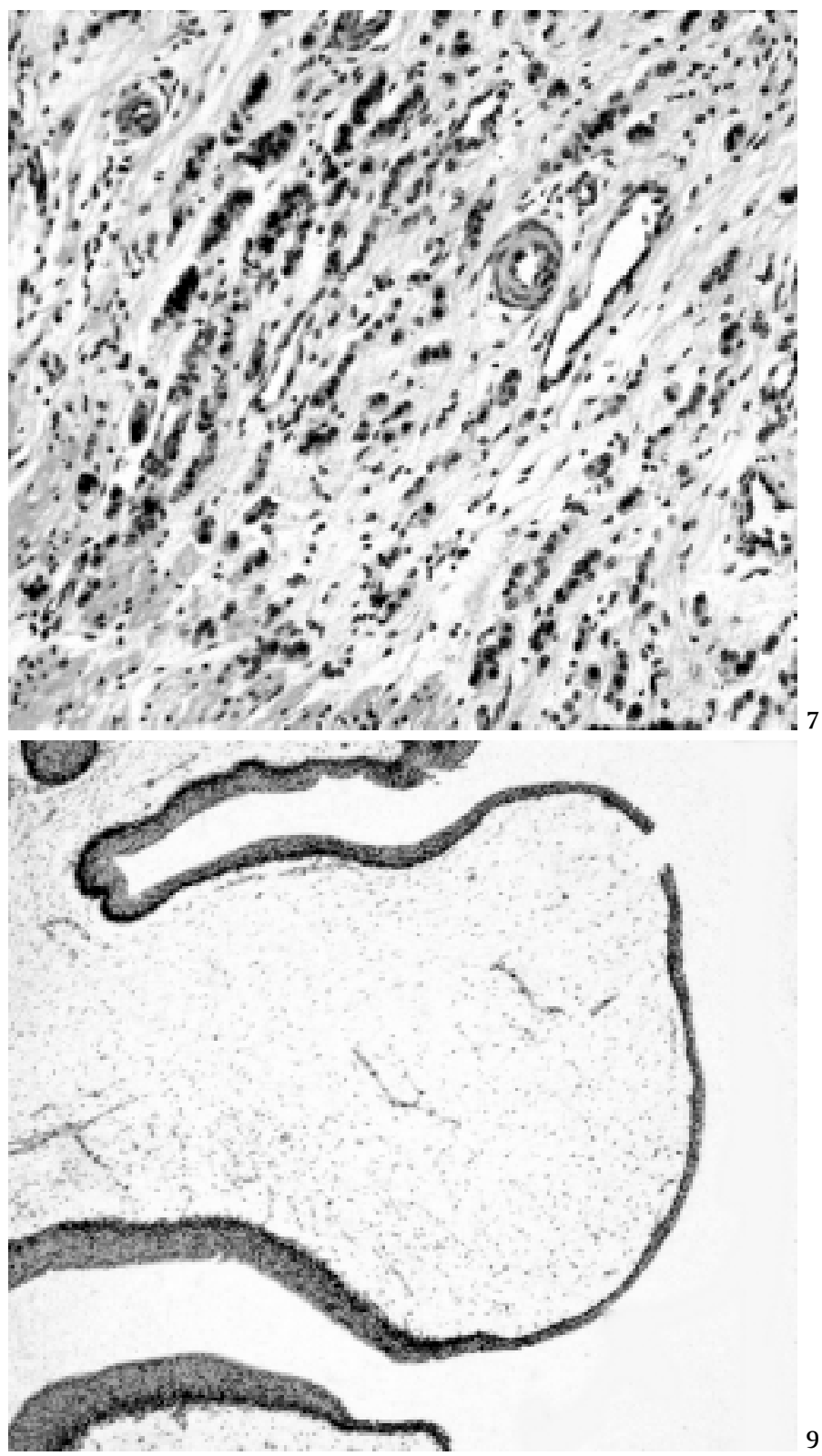

Fig. 7. Scirrhous trabecular carcinoma infiltrating the destrusor muscle in BEH (Bov. 4862, 24496). HE, obj. 16.

Fig. 9. Polypoid proliferation with urothelial hyperplasia and myxoid stroma in BEH (Bov. 4862, 24496). HE, obj. 4.

examinated bladders. In a consistant way, predominantly lymphocytic inflammatory infiltration, sometimes accompanied by plasmocytes, diffuse and/or in the form of lymphoid follicles, went with the phenomena of cellular proliferation, amid variable degrees of fibroplasia of the propria among the muscle fascicles (detrusor muscle) and even at the serosa. In summary, the diversity and the coexistence of the different histological alterations can be seen in the tables. 
Table 1. Malignant neoplasms associated with BEH in Brazil

\begin{tabular}{|c|c|c|c|c|c|c|c|c|c|c|c|}
\hline Protocol & $\begin{array}{l}\text { Carcinoma } \\
\text { "in situ" }\end{array}$ & $\begin{array}{cc}\text { a Transitional } & \mathrm{Sc} \\
\text { carcinoma } & \mathrm{ca}\end{array}$ & $\begin{array}{l}\text { Squamous } \\
\text { carcinoma }\end{array}$ & $\begin{array}{l}\text { Trabecular } \\
\text { carcinoma }\end{array}$ & $\begin{array}{c}\text { Poorly } \\
\text { differentiated } \\
\text { carcinoma }\end{array}$ & $\begin{array}{c}\text { Adeno } \\
\text { carcinoma }\end{array}$ & $\begin{array}{l}\text { Mesonephroid } \\
\text { adenocarcinoma }\end{array}$ & $\begin{array}{c}\text { Carcinoma } \\
\text { with spindle } \\
\text { cell stroma }\end{array}$ & $\begin{array}{c}\text { Other types } \\
\text { of carcinomas }\end{array}$ & $\begin{array}{l}\text { Hemangio } \\
\text { sarcoma }\end{array}$ & Differentiation \\
\hline $\begin{array}{l}\text { Bovine } 4862 \\
\quad 24496\end{array}$ & + & $\begin{array}{c}{ }^{*} \\
\text { (high grade) }\end{array}$ & - & $+*$ & $\begin{array}{l}+ \text { with big and } \\
\text { isolated cells }\end{array}$ & $++^{* * * * *}$ & + & - & $\begin{array}{l}\text { Signet ring cell } \\
\text { carcinoma } \\
\text { Plasmacytoid } \\
\text { carcinoma }\end{array}$ & $*$ & $\begin{array}{c}\text { * pseudoglandular } \\
* * \text { Paneth } \\
* * \text { intestinal and } \\
\text { Paneth }\end{array}$ \\
\hline $\begin{array}{l}\text { Bovine } 4863 \\
\quad 24498\end{array}$ & + & $\begin{array}{l}+ \text { "'(high grade) } \\
\text { vith pseudo-sarco- } \\
\text { matous stroma }\end{array}$ & + & - & + & - & + & - & $\begin{array}{l}\text { Transitional cell } \\
\text { carcinoma, } \\
\text { nested type }\end{array}$ & - & * pseudoglandular \\
\hline $\begin{array}{l}\text { Bovine } 4864 \\
24581\end{array}$ & + & $\begin{array}{c}+^{*} \\
\text { (high grade) }\end{array}$ & $+* * *$ & - & + & - & - & - & $\begin{array}{c}\text { Sarcomatoid } \\
\text { carcinoma or } \\
\text { carcinosarcoma? }\end{array}$ & + & $\begin{array}{c}\text { "pseudoglandular, } \\
\text { mesonephroid } \\
\text { and intestinal } \\
\text { pseudoglandular }\end{array}$ \\
\hline $\begin{array}{l}\text { Bovine } 4865 \\
\quad 24582\end{array}$ & + & $\begin{array}{c}+^{*} \\
\text { (high grade) }\end{array}$ & $+* *$ & - & - & - & - & - & - & - & $\begin{array}{l}\text { "pseudoglandular, } \\
\text { mesonephroid } \\
\text { and intestinal } \\
\text { pseudoglandular }\end{array}$ \\
\hline 18207 & - & - & - & - & - & - & - & - & - & - & \\
\hline $\begin{array}{c}\text { Bovine } 2145 \\
16759-60\end{array}$ & - & - & - & - & $+^{*}$ & - & - & - & - & - & $\begin{array}{l}\text { "pseudoglandular } \\
\text { and squamous }\end{array}$ \\
\hline 20667 & _- & _- & _- & _ & _- & _ & _- & _- & _- & + & - \\
\hline 20289 & & - & _- & - & - & _- & _- & _- & _- & _- & - \\
\hline 20896 & $\bar{t}$ & $\begin{array}{l}- \\
-\end{array}$ & - & - & $\begin{array}{c}+* \\
\text { with bizarre cells }\end{array}$ & - & - & - & - & - & $\begin{array}{l}\text { "pseudoglandular } \\
\text { and squamous }\end{array}$ \\
\hline 28231 & + & $\begin{array}{l}+ \text { (high grade) } \\
\text { vith pseudo-sarco- } \\
\text { matous stroma }\end{array}$ & - & $+*$ & - & - & - & - & - & - & "squamous \\
\hline 29056 & + & $\begin{array}{c}{ }^{+*} \\
\text { (high grade) }\end{array}$ & - & - & - & - & - & - & - & - & $\begin{array}{l}\text { "squamous, } \\
\text { mesonephroid } \\
\text { and intestinal }\end{array}$ \\
\hline $\begin{array}{c}866 \\
\text { Paraná }\end{array}$ & + & $\begin{array}{l}+* \text { (high grade) } \\
\text { vith pseudo-sarco- } \\
\text { matous stroma }\end{array}$ & - & - & - & $+{ }^{* * * *}$ & + & $\begin{array}{c}+ \\
\text { (transitional) }\end{array}$ & - & - & $\begin{array}{l}\text { "pseudoglandular } \\
\text { "**" intestinal }\end{array}$ \\
\hline 920 & & & & & & & & & & & \\
\hline Paraná & + & $\begin{array}{c}{ }^{* *} \\
\text { (high grade) }\end{array}$ & $+*$ & - & - & - & - & - & - & - & $\begin{array}{l}\text { "pseudoglandular, } \\
\text { mesonephroid } \\
\text { and intestinal } \\
\text { peudoglandular }\end{array}$ \\
\hline 29279 & - & - & _- & - & - & _- & - & _- & _- & + & _ \\
\hline 28196 & $\begin{array}{l}+ \text { multi } \\
\text { centric }\end{array}$ & $\begin{array}{c}+ \\
\text { (high grade) }\end{array}$ & - & - & - & - & - & - & - & + & - \\
\hline Vn-65-77 & _- & - & _- & - & _- & - & - & - & _- & - & _- \\
\hline V-214-83 & + & $\begin{array}{c}{ }^{+*} \\
\text { (high grade) }\end{array}$ & - & - & - & - & $+* *$ & $\begin{array}{l}- \\
-\end{array}$ & $\begin{array}{l}\text { Chromophobe } \\
\text { cell carcinoma }\end{array}$ & $\begin{array}{l}- \\
- \\
-\end{array}$ & $\begin{array}{c}* \text { chromophobe cell, } \\
\text { pseudoglandular, } \\
\text { squamous } \\
* * \text { chromophobe cell }\end{array}$ \\
\hline V-328-84 & - & - & - & - & _- & - & - & - & _- & - & - \\
\hline V-65-87 & - & - & - & - & - & - & - & - & _- & - & - \\
\hline V-211-87 & + & $\begin{array}{c}{ }^{+*} \\
\text { (high grade) }\end{array}$ & - & - & - & - & - & - & - & - & $\begin{array}{l}* \text { intestinal and } \\
\text { pseudoglandular }\end{array}$ \\
\hline V-563-89 & - & - & - & - & - & - & - & - & - & - & - \\
\hline V-36-90 & + & - & - & - & - & - & - & - & $\begin{array}{l}\text { Sarcomatoid } \\
\text { carcinoma? }\end{array}$ & - & - \\
\hline V-4-94 & - & - & - & - & - & - & - & - & _- & _- & - \\
\hline V-265-90 & ${ }^{-}$ & $\begin{array}{l}+(\text { high grade }) \\
\text { vith pseudo-sarco- } \\
\text { matous stroma }\end{array}$ & + & - & - & $+*$ & - & - & - & + & * intestinal \\
\hline V-266-90 & + & $\begin{array}{c}+^{*} \\
\text { (high grade) }\end{array}$ & $+* *$ & - & - & - & - & - & - & + & $\begin{array}{l}\text { *pseudoglandular } \\
\text { ** pseudoglandular }\end{array}$ \\
\hline V-269-90 & - & $\begin{array}{c}{ }^{*} \\
\text { (high grade) }\end{array}$ & $+* *$ & - & + & - & - & $\begin{array}{c}+ \\
\text { (squamous) }\end{array}$ & - & - & $\begin{array}{l}\text { *pseudoglandular, } \\
\text { intestinal and } \\
\text { mesonephroid } \\
\text { **pseudoglandular }\end{array}$ \\
\hline V-270-90 & + & $\begin{array}{l}+^{*}(\text { high grade }) \\
\text { vith pseudo-sarco- } \\
\text { matous stroma }\end{array}$ & + & - & - & - & - & - & $\begin{array}{l}\text { Sarcomatoid carci- } \\
\text { noma with syncytio- } \\
\text { trophoblastic cells? }\end{array}$ & $\begin{array}{l}\text { i- } \\
\text { o- } \\
\text { ? }\end{array}$ & $\begin{array}{l}\text { * squamous and } \\
\text { intestinal }\end{array}$ \\
\hline V-271-90 & - & $\begin{array}{c}{ }^{*} \\
\text { (high grade) }\end{array}$ & - & - & + & - & + & - & - & - & $\begin{array}{l}\text { * squamous and } \\
\text { pseudoglandular }\end{array}$ \\
\hline V-272-90 & + & $\begin{array}{c}\text { +* }^{*} \\
\text { (high grade) }\end{array}$ & - & - & - & - & - & - & - & + & $\begin{array}{l}\text { * squamous and } \\
\text { pseudoglandular }\end{array}$ \\
\hline
\end{tabular}

Pesq. Vet. Bras. 23(2):65-81, abr./jun. 2003 
Table 1. Malignant neoplasms associated with BEH in Brazil (Continuation)

\begin{tabular}{|c|c|c|c|c|c|c|c|c|c|c|c|}
\hline Protocol & $\begin{array}{l}\text { Carcinoma } \\
\text { "in situ" }\end{array}$ & $\begin{array}{c}\text { Transitional } \\
\text { carcinoma }\end{array}$ & $\begin{array}{l}\text { Squamous } \\
\text { carcinoma }\end{array}$ & $\begin{array}{l}\text { Trabecular } \\
\text { carcinoma }\end{array}$ & $\begin{array}{c}\text { Poorly } \\
\text { differentiated } \\
\text { carcinoma }\end{array}$ & $\begin{array}{c}\text { Adeno } \\
\text { carcinoma }\end{array}$ & $\begin{array}{l}\text { Mesonephroid } \\
\text { adenocarcinoma }\end{array}$ & $\begin{array}{l}\text { Carcinoma } \\
\text { with spindle } \\
\text { cell stroma }\end{array}$ & $\begin{array}{l}\text { Other types } \\
\text { of carcinomas }\end{array}$ & $\begin{array}{l}\text { Hemangio- } \\
\text { sarcoma }\end{array}$ & Differentiation \\
\hline V-273-90 & $-^{\mathrm{a}}$ & - & $\begin{array}{l}{ }^{+*} \\
\text { focal mine- } \\
\text { ralixation }\end{array}$ & - & - & - & - & - & - & - & "pseudoglandular \\
\hline V-274-90 & + & $\begin{array}{c}{ }^{* *} \\
\text { (high grade) }\end{array}$ & + & - & - & - & - & - & - & + & $\begin{array}{l}\text { " squamous and } \\
\text { pseudoglandular }\end{array}$ \\
\hline V-275-90 & - & $\begin{array}{c}+ \\
\text { (low grade) }\end{array}$ & - & - & - & - & - & - & - & - & - \\
\hline V-276-90 & + & - & _ & _ & _ & _ & _ & _ & _ & + & \\
\hline V-277-90 & $\begin{array}{l}+ \text { multi } \\
\text { centric }\end{array}$ & $\begin{array}{c}+^{-*} \\
\text { (high grade) }\end{array}$ & $\begin{array}{l}- \\
-\end{array}$ & $\begin{array}{l}- \\
-\end{array}$ & $\begin{array}{l}- \\
-\end{array}$ & $\begin{array}{l}- \\
-\end{array}$ & - & $\begin{array}{l}- \\
-\end{array}$ & - & - & $\begin{array}{l}\text { "pseudoglandular } \\
\text { and squamous }\end{array}$ \\
\hline V-278-90 & + & $\begin{array}{c}+* \\
\text { (high grade) }\end{array}$ & - & - & - & - & - & - & - & - & " mesonephroid \\
\hline V-448-90 & - & $\begin{array}{c}+* \\
\text { (high grade) }\end{array}$ & - & - & - & $+* *$ & - & - & - & - & $\begin{array}{l}\text { " pseudoglandular } \\
\text { and squamous } \\
\text { "*** intestinal }\end{array}$ \\
\hline 24762 & + & _- & _- & _- & _- & _- & _- & _- & _- & _- & _- \\
\hline 24765 & - & - & _- & _- & _- & _- & _- & _- & - & _- & _- \\
\hline 24796 & + & $\begin{array}{c}+* \\
\text { (high grade) }\end{array}$ & - & - & - & - & - & - & - & $\begin{array}{l}\text { + with syncy- } \\
\text { tiotrophobl } \\
\text { astic cells }\end{array}$ & $\begin{array}{c}\text { "squamous, } \\
\text { pseudoglandular } \\
\text { and mesonephroid }\end{array}$ \\
\hline V-234-91 & - & - & - & - & - & - & - & - & - & - & - \\
\hline $\begin{array}{c}\text { Bovine } 823 \\
13694,13775 \\
-79,17806\end{array}$ & - & - & - & - & - & - & - & - & - & - & - \\
\hline $\begin{array}{c}\text { Bovine } 874 \\
14768-70\end{array}$ & + & - & - & - & - & - & - & - & - & + & - \\
\hline $\begin{array}{c}\text { Bovine } 961 \\
15302-05 \\
17807\end{array}$ & - & - & - & - & - & - & - & - & - & + & - \\
\hline $\begin{array}{c}\text { Bovine } 2377 \\
18238-42\end{array}$ & + & $\begin{array}{c}+* \\
\text { (low grade) }\end{array}$ & - & - & - & - & - & - & - & - & "pseudoglandular \\
\hline $\begin{array}{c}\text { Bovine } 2379 \\
18245-47\end{array}$ & - & $\begin{array}{c}+* \\
\text { (low grade) }\end{array}$ & - & - & - & + & - & - & - & + & * intestinal \\
\hline Bovine 2380 & & & & & & & & & & & \\
\hline 18248-51 & - & & - & - & - & - & - & - & - & - & - \\
\hline $\begin{array}{c}\text { Bovine } 2381 \\
18252-53\end{array}$ & $\overline{+}$ & $\begin{array}{c}{ }^{-*} \\
\text { (moderate grade) }\end{array}$ & - & - & - & - & - & - & - & - & $\begin{array}{l}\text { " squamous, me- } \\
\text { sonephroid and } \\
\text { pseudoglandular }\end{array}$ \\
\hline $\begin{array}{l}\text { Bovine } 2396 \\
18394-18301\end{array}$ & - & - & - & - & - & - & - & - & - & - & - \\
\hline $\begin{array}{c}\text { Bovine } 2188 \\
17422-24 \\
17808\end{array}$ & - & - & - & - & - & - & - & - & - & + & - \\
\hline $\begin{array}{c}\text { Bovine } 2286 \\
17863-67\end{array}$ & - & - & - & - & - & - & - & - & - & + & - \\
\hline $\begin{array}{c}\text { Bovine } 2291 \\
17898-900 / \\
17911\end{array}$ & - & - & - & - & - & - & - & - & - & - & - \\
\hline $\begin{array}{c}\text { Bovine } 2303 \\
17907-910\end{array}$ & - & - & - & - & - & - & - & - & - & - & - \\
\hline $\begin{array}{c}\text { Bovine } 2285 \\
17857-62\end{array}$ & - & - & - & - & - & - & - & - & - & - & - \\
\hline $\begin{array}{c}\text { Bovine } 2287 \\
17868-70\end{array}$ & - & - & - & - & - & - & - & - & - & - & - \\
\hline $\begin{array}{c}\text { Bovine } 2371 \\
18231-33\end{array}$ & - & - & - & - & - & - & - & - & - & - & - \\
\hline $\begin{array}{c}\text { Bovine } 2374 \\
18234-36\end{array}$ & - & - & - & - & - & - & - & - & - & - & - \\
\hline $\begin{array}{c}\text { Bovine } 2376 \\
\quad 18237\end{array}$ & - & - & - & - & - & - & - & - & - & - & - \\
\hline $\begin{array}{c}\text { Bovine } 2382 \\
18254-56\end{array}$ & - & - & - & - & - & - & - & - & - & - & - \\
\hline $\begin{array}{l}\text { Bovine } 2385 \\
\quad 18257\end{array}$ & - & - & - & - & - & - & - & - & - & - & - \\
\hline
\end{tabular}

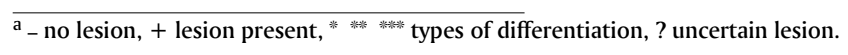


Table 2. Benign neoplasms associated with BEH in Brazil

\begin{tabular}{|c|c|c|c|c|c|c|c|}
\hline Protocol & Transitional & $\begin{array}{c}\text { Transitional } \\
\text { papilloma }\end{array}$ & $\begin{array}{c}\text { Mesonephroid } \\
\text { adenoma }\end{array}$ & $\begin{array}{l}\text { Capillary } \\
\text { adenoma }\end{array}$ & $\begin{array}{c}\text { Cavernous } \\
\text { hemangioma }\end{array}$ & $\begin{array}{c}\text { Venous } \\
\text { hemangioma }\end{array}$ & $\begin{array}{c}\text { Myxoma } \\
\text { hemangioma }\end{array}$ \\
\hline $\begin{array}{l}\text { Bovine } 4862 \\
24496\end{array}$ & - & - & + & - & - & - & - \\
\hline $\begin{array}{l}\text { Bovine } 4863 \\
\quad 24498\end{array}$ & $\begin{array}{l}+ \\
\text { with mesonephroid } \\
\text { differentiation }\end{array}$ & - & + & - & - & - & - \\
\hline $\begin{array}{l}\text { Bovine } 4864 \\
24581\end{array}$ & + & + & - & + & + & - & - \\
\hline $\begin{array}{l}\text { Bovine } 4865 \\
\quad 24582\end{array}$ & - & - & - & - & + & - & - \\
\hline 18207 & - & - & - & - & - & - & - \\
\hline $\begin{array}{c}\text { Bovine } 2145 \\
16759-60\end{array}$ & + & - & - & - & - & - & - \\
\hline 20667 & - & - & _- & - & - & - & - \\
\hline 20289 & $\begin{array}{c}+ \\
\text { with mesonephroid } \\
\text { differentiation }\end{array}$ & - & - & - & + & - & - \\
\hline 20896 & - & - & - & - & - & - & - \\
\hline 28231 & - & - & - & - & + & - & - \\
\hline 29056 & - & - & - & - & - & - & - \\
\hline $\begin{array}{l}866 \\
\text { Paraná }\end{array}$ & $\begin{array}{l}\text { with intestinal } \\
\text { differentiation }\end{array}$ & + & - & - & - & - & - \\
\hline $\begin{array}{c}920 \\
\text { Paraná }\end{array}$ & - & - & - & - & - & - & - \\
\hline 29279 & + & - & - & + & + & - & - \\
\hline 28196 & + & + & _- & _- & _- & _- & - \\
\hline Vn -65-77 & - & - & - & - & - & + & - \\
\hline V-214-83 & - & - & - & - & - & - & - \\
\hline V-328-84 & + & - & - & - & - & - & - \\
\hline V-65-87 & - & - & - & + & - & - & - \\
\hline V-211-87 & + & - & - & - & - & - & - \\
\hline V-563-89 & - & - & - & - & - & + & - \\
\hline V-36-90 & - & - & - & - & - & - & - \\
\hline Vn-4-94 & + & - & - & - & - & - & - \\
\hline V-265-90 & + & - & - & + & - & - & - \\
\hline V-266-90 & - & - & - & - & + & + & - \\
\hline V-269-90 & - & - & - & - & + & - & - \\
\hline V-270-90 & - & - & - & - & - & - & - \\
\hline V-271-90 & - & - & - & - & - & + & - \\
\hline V-272-90 & - & - & - & - & - & - & - \\
\hline V-273-90 & - & - & - & - & - & - & - \\
\hline V-274-90 & - & - & - & - & - & - & - \\
\hline V-275-90 & + & - & - & - & - & + & - \\
\hline V-276-90 & - & - & - & + & + & + & + \\
\hline V-277-90 & - & - & - & - & - & + & - \\
\hline V-278-90 & - & - & - & - & - & - & - \\
\hline V-448-90 & - & - & - & - & - & - & - \\
\hline 24762 & - & - & - & + & + & - & - \\
\hline
\end{tabular}




\section{DISCUSSION}

The diversity of the neoplasms observed in bovines with BEH is surprising, especially when we consider the small variation in the occurrence of bladder tumors in other species of domestic animals. On the other hand, there is almost a perfect identity with the neoplastic processes that are found in the human bladder. Almost the only significant differences were in the frequency in some processes seen in the bladder of cattle with BEH compared to humans.

It is very likely that in human bladder tumors the variability is associated to the three embryonic segments that participate in the formation of the bladder, which are portions of the mesonephric ducts, the mesenchyma that surrounds the urogenital protuberance and the infra-umbi-

Table 2. Benign neoplasms associated with BEH in Brazil (Continuation)

\begin{tabular}{|c|c|c|c|c|c|c|c|}
\hline Protocol & $\begin{array}{l}\text { Transitional } \\
\text { papilloma }\end{array}$ & $\begin{array}{c}\text { Transitional } \\
\text { adenoma }\end{array}$ & $\begin{array}{l}\text { Mesonephroid } \\
\text { adenoma }\end{array}$ & $\begin{array}{c}\text { Capillary } \\
\text { hemangioma }\end{array}$ & $\begin{array}{c}\text { Cavernous } \\
\text { hemangioma }\end{array}$ & $\begin{array}{c}\begin{array}{c}\text { Venous } \\
\text { hemangioma }\end{array} \\
\end{array}$ & $\begin{array}{r}\text { Myxoma } \\
\text { hemangioma }\end{array}$ \\
\hline 24765 & $-^{\mathrm{a}}$ & - & - & - & + & - & - \\
\hline 24796 & - & - & - & - & - & - & - \\
\hline V-234-91 & - & - & - & - & - & - & - \\
\hline $\begin{array}{l}\text { Bovine } 823 \\
13694,13775-79, \\
17806\end{array}$ & - & - & - & - & - & - & - \\
\hline $\begin{array}{c}\text { Bovine } 874 \\
14768-70\end{array}$ & - & - & - & + & + & + & - \\
\hline $\begin{array}{l}\text { Bovine } 961 \\
15302-05,17807\end{array}$ & - & - & - & + & + & + & - \\
\hline $\begin{array}{c}\text { Bovine } 2377 \\
18238-42\end{array}$ & - & + & - & - & - & - & - \\
\hline $\begin{array}{c}\text { Bovine } 2379 \\
18245-47\end{array}$ & - & + & - & + & + & + & - \\
\hline $\begin{array}{c}\text { Bovine } 2380 \\
18248-51\end{array}$ & - & - & - & - & - & - & + \\
\hline $\begin{array}{c}\text { Bovine2381 } \\
18252-53\end{array}$ & + & + & - & + & - & - & - \\
\hline $\begin{array}{l}\text { Bovine } 2396 \\
18294-18301\end{array}$ & - & - & - & - & - & - & - \\
\hline $\begin{array}{l}\text { Bovine } 2188 \\
17422-24,17808\end{array}$ & - & - & - & + & - & + & - \\
\hline $\begin{array}{c}\text { Bovine } 2286 \\
17863-67\end{array}$ & - & - & - & - & - & + & - \\
\hline $\begin{array}{l}\text { Bovine } 2291 \\
17898-00,17911\end{array}$ & - & - & - & - & - & - & - \\
\hline $\begin{array}{c}\text { Bovine } 2303 \\
17907-10\end{array}$ & - & - & - & - & - & - & - \\
\hline $\begin{array}{c}\text { Bovine } 2285 \\
17857-62\end{array}$ & - & - & - & - & - & - & - \\
\hline $\begin{array}{c}\text { Bovine } 2287 \\
17868-70\end{array}$ & - & - & - & - & - & - & - \\
\hline $\begin{array}{c}\text { Bovine } 2371 \\
18231-33\end{array}$ & - & - & - & - & - & - & - \\
\hline $\begin{array}{c}\text { Bovine } 2374 \\
18234-36\end{array}$ & - & - & - & - & - & - & - \\
\hline $\begin{array}{c}\text { Bovine } 2376 \\
18237\end{array}$ & - & - & - & - & - & - & - \\
\hline $\begin{array}{c}\text { Bovine 2382 } \\
18254-56\end{array}$ & - & - & - & - & - & - & - \\
\hline $\begin{array}{c}\text { Bovine } 2385 \\
18257\end{array}$ & - & - & - & - & - & - & - \\
\hline
\end{tabular}


Table 3. Non-neoplastic lesions associated with BEH in Brazil

\begin{tabular}{|c|c|c|c|c|c|c|c|c|c|}
\hline Protocol & Urothelial & $\begin{array}{c}\text { Urothelial } \\
\text { hyperplasia }\end{array}$ & $\begin{array}{l}\text { Metaplasia } \mathrm{B} \\
\text { dysplasia }\end{array}$ & Brunn nests & $\begin{array}{l}\text { Cystitis } \\
\text { cystica }\end{array}$ & $\begin{array}{c}\text { Cystitis } \\
\text { glandularis }\end{array}$ & $\begin{array}{c}\text { Polypoid } \\
\text { proliferation }\end{array}$ & $\begin{array}{c}\text { Micropolypoid } \\
\text { proliferation }\end{array}$ & $\begin{array}{c}\text { Intraepithelial } \\
\text { cysts }\end{array}$ \\
\hline $\begin{array}{c}\text { Bovine } 4862 \\
24496\end{array}$ & ++ & $\begin{array}{l}\text { Grade II } \\
\text { and III }\end{array}$ & $\begin{array}{l}\text { intestinal and } \\
\text { mesonephroid }\end{array}$ & + & + & + & +++ & - & $(+)$ \\
\hline $\begin{array}{c}\text { Bovine } 4863 \\
24498\end{array}$ & $+(+)$ & Grade III & mesonephroid & + & + & - & + & + & +++ \\
\hline $\begin{array}{c}\text { Bovine } 4864 \\
24581\end{array}$ & ++ & Grade III & intestinal & + & + & + & + & - & ++ \\
\hline $\begin{array}{c}\text { Bovine } 4865 \\
24582\end{array}$ & ++ & $\begin{array}{l}\text { Grade II } \\
\text { and III }\end{array}$ & intestinal & + & + & + & + & - & $(+)$ \\
\hline 18207 & $(+)$ & - & - & - & - & - & + & - & - \\
\hline $\begin{array}{c}\text { Bovine } 2145 \\
16759-60\end{array}$ & + & - & - & - & - & - & + & + & - \\
\hline 20667 & $+(+)$ & Grade III & $\begin{array}{c}\text { mesonephroid } \\
\text { and chromo- } \\
\text { phobe cell }\end{array}$ & d & - & - & - & - & - \\
\hline 20289 & ++ & $\begin{array}{c}\text { Grade I } \\
\text { and II }\end{array}$ & mesonephroid & $(+)$ & $(+)$ & - & $+(+)$ & $(+)$ & ++ \\
\hline 20896 & $+(+)$ & $\begin{array}{c}\text { Grade I } \\
\text { and II }\end{array}$ & squamous & ++ & ++ & - & $+(+)$ & - & ++ \\
\hline 28231 & - & - & - & - & - & - & - & - & + \\
\hline 29056 & ++ & Grade III & - & $(+)$ & $(+)$ & - & $(+)$ & - & - \\
\hline $\begin{array}{c}866 \\
\text { Paraná } \\
920\end{array}$ & ++ & Grade III & intestinal & + & + & + & - & - & - \\
\hline Paraná & + & Grade III & intestinal & + & + & + & - & - & $(+)$ \\
\hline 29279 & ++ & $\begin{array}{l}\text { Grade I } \\
\text { and II }\end{array}$ & - & $(+)$ & $(+)$ & - & + & + & $(+)$ \\
\hline 28196 & ++ & $\begin{array}{c}\text { Grade III } \\
\text { with binu- } \\
\text { cleate cells }\end{array}$ & - & + & $(+)$ & - & $+(+)$ & - & - \\
\hline Vn-65-77 & - & - & - & - & - & - & - & - & - \\
\hline V-214-83 & + & $\begin{array}{c}\text { Grade II } \\
\text { and III }\end{array}$ & - & - & - & - & $(+)$ & - & $(+)$ \\
\hline V-328-84 & + & - & - & $(+)$ & $(+)$ & - & + & - & $(+)$ \\
\hline V-65-87 & ++ & $\begin{array}{l}\text { Grade II } \\
\text { and III }\end{array}$ & $\begin{array}{l}\text { chromophobe } \\
\text { cell }\end{array}$ & $(+)$ & - & - & $(+)$ & - & $(+)$ \\
\hline V-211-87 & ++ & $\begin{array}{l}\text { Grade II } \\
\text { and III }\end{array}$ & - & + & + & - & + & - & + \\
\hline V-563-89 & - & - & - & - & - & - & - & - & - \\
\hline V-36-90 & ++ & $\begin{array}{l}\text { Grade I } \\
\text { and II }\end{array}$ & - & - & - & - & + & - & $(+)$ \\
\hline Vn-4-94 & - & - & - & - & - & - & - & - & $(+)$ \\
\hline V-265-90 & + & - & + & + & + & + & + & + & - \\
\hline V-266-90 & - & - & - & + & + & - & - & - & - \\
\hline V-269-90 & + & - & intestinal & - & - & - & - & - & - \\
\hline V-270-90 & - & - & - & - & - & - & + & - & - \\
\hline V-271-90 & - & - & - & + & - & - & - & - & - \\
\hline V-272-90 & + & - & - & - & - & - & - & - & - \\
\hline V-273-90 & + & - & - & - & - & - & - & - & - \\
\hline V-274-90 & - & - & - & + & + & - & - & - & - \\
\hline V-275-90 & $+(+)$ & - & - & + & + & - & + & - & - \\
\hline
\end{tabular}


Table 3. Non-neoplastic lesions associated with BEH in Brazil (Continuation)

\begin{tabular}{|c|c|c|c|c|c|c|c|c|c|}
\hline Protocol & $\begin{array}{c}\text { Urothelial } \\
\text { hyperplasia }\end{array}$ & $\begin{array}{c}\text { Urothelial } \\
\text { dysplasia }\end{array}$ & Metaplasia & Brunn nests & $\begin{array}{l}\text { Cystitis } \\
\text { cystica }\end{array}$ & $\begin{array}{c}\text { Cystitis } \\
\text { glandularis }\end{array}$ & $\begin{array}{c}\text { Polypoid } \\
\text { proliferation }\end{array}$ & $\begin{array}{c}\text { Micropolypoid } \\
\text { proliferation }\end{array}$ & $\begin{array}{c}\text { Intraepithelial } \\
\text { cysts }\end{array}$ \\
\hline V-276-90 & $+^{a}$ & $\begin{array}{l}\text { Grade II } \\
\text { and III }\end{array}$ & - & + & + & - & + & - & $(+)$ \\
\hline V-277-90 & + & $\begin{array}{l}\text { Grade I } \\
\text { and II }\end{array}$ & - & + & - & - & + & - & + \\
\hline V-278-90 & $(+)+$ & Grade II & _ & + & + & _- & ++ & $(+)$ & ++ \\
\hline V-448-90 & - & - & - & - & - & - & + & - & ++ \\
\hline 24762 & $+(+)$ & Grade III & - & - & - & - & - & - & $(+)$ \\
\hline 24765 & - & - & - & - & - & - & - & - & - \\
\hline 24796 & + & $\begin{array}{l}\text { Grade II } \\
\text { and III }\end{array}$ & mesonephroid & $(+)$ & - & - & + & - & $(+)$ \\
\hline V-234-91 & $(+)$ & Grade III & _ & $(+)$ & _- & _- & _- & + & $(+)$ \\
\hline $\begin{array}{c}\text { Bovine } 823 \\
13694,13775-79 \\
17806\end{array}$ & - & - & - & - & - & - & $(+)$ & - & $(+)$ \\
\hline $\begin{array}{c}\text { Bovine } 874 \\
14768-70\end{array}$ & ++ & $\begin{array}{l}\text { Grade II } \\
\text { and III }\end{array}$ & - & $+(+)$ & + & - & $+(+)$ & - & ++ \\
\hline $\begin{array}{l}\text { Bovine } 961 \\
15302-05,17807\end{array}$ & $+(+)$ & Grade I & - & $(+)$ & - & - & - & $(+)$ & + \\
\hline $\begin{array}{c}\text { Bovine } 2377 \\
18238-42\end{array}$ & + & Grade III & mesonephroid & d $\quad+(+)$ & + & - & ++ & - & - \\
\hline $\begin{array}{c}\text { Bovine } 2379 \\
18245-47\end{array}$ & + & $\begin{array}{l}\text { Grade II } \\
\text { and III }\end{array}$ & mesonephroid & ++ & ++ & - & + & - & - \\
\hline $\begin{array}{c}\text { Bovine } 2380 \\
18248-51\end{array}$ & ++ & - & - & $(+)$ & $(+)$ & - & + & - & - \\
\hline $\begin{array}{c}\text { Bovine } 2381 \\
18252-53\end{array}$ & ++ & Grade III & $\begin{array}{l}\text { mesonephroid } \\
\text { and chromo- } \\
\text { phobe cell }\end{array}$ & ++ & ++ & - & ++ & - & + \\
\hline $\begin{array}{l}\text { Bovine } 2396 \\
18394-18301\end{array}$ & $(+)$ & Grade I & - & $(+)$ & - & - & - & + & - \\
\hline $\begin{array}{l}\text { Bovine } 2188 \\
17422-24,17808\end{array}$ & $(+)$ & Grade I & - & $(+)$ & - & - & - & $(+)$ & - \\
\hline $\begin{array}{c}\text { Bovine } 2286 \\
17863-67\end{array}$ & + & Grade I & - & $+(+)$ & - & - & +++ & +++ & - \\
\hline $\begin{array}{c}\text { Bovine } 2291 \\
17898-900 \\
17911\end{array}$ & $(+)$ & - & $\begin{array}{l}\text { mesonephroid } \\
\text { and chromo- } \\
\text { phobe cell }\end{array}$ & $(+)$ & - & - & - & + & - \\
\hline $\begin{array}{c}\text { Bovine } 2303 \\
17907-910\end{array}$ & ++ & Grade II & - & $(+)$ & - & - & $(+)$ & - & - \\
\hline $\begin{array}{c}\text { Bovine } 2285 \\
17857-62\end{array}$ & $(+)$ & Grade II & - & $(+)$ & - & - & - & $(+)$ & - \\
\hline $\begin{array}{c}\text { Bovine } 2287 \\
17868-70\end{array}$ & + & - & - & $(+)$ & - & - & ++ & $+(+)$ & - \\
\hline $\begin{array}{c}\text { Bovine } 2371 \\
18231-33\end{array}$ & $(+)$ & - & - & $(+)$ & - & - & $+(+)$ & + & - \\
\hline $\begin{array}{c}\text { Bovine } 2374 \\
18234-36\end{array}$ & $(+)$ & - & - & + & - & - & ++ & $(+)$ & - \\
\hline $\begin{array}{c}\text { Bovine } 2376 \\
18237\end{array}$ & $(+)$ & - & - & $(+)$ & - & - & + & - & - \\
\hline $\begin{array}{c}\text { Bovine } 2382 \\
18254-56\end{array}$ & - & - & - & - & - & - & - & - & - \\
\hline $\begin{array}{c}\text { Bovine } 2385 \\
18257\end{array}$ & $(+)$ & - & - & - & - & - & - & $(+)$ & - \\
\hline
\end{tabular}

a no lesion, $(+)$ very low, + low, $+(+)$ low to moderate, ++ moderate, $++(+)$ moderate to high, +++ high-grade, ? uncertain lesion. 
Table 4. Non-neoplastic lesions associated with BEH in Brazil

\begin{tabular}{|c|c|c|c|c|c|c|c|c|}
\hline Protocol & $\begin{array}{l}\text { Vascular } \\
\text { proliferation }\end{array}$ & $\begin{array}{l}\text { Vascular } \\
\text { ectasy }\end{array}$ & Hemorrhage & $\begin{array}{l}\text { Lymphocytic } \\
\text { focus }\end{array}$ & $\begin{array}{c}\text { Diffuse lymphocytic } \\
\text { infiltration }\end{array}$ & Fibrosis & $\begin{array}{l}\text { Myxoid } \\
\text { stroma }\end{array}$ & $\begin{array}{l}\text { Inflammatory } \\
\text { pseudotumor }\end{array}$ \\
\hline $\begin{array}{l}\text { Bovine } 4862 \\
\quad 24496\end{array}$ & $\begin{array}{l}++ \text { sanguineous } \\
\text { and lymphatic }\end{array}$ & $(+)$ & ++ & + & + & $\begin{array}{c}+++ \\
\text { lamina propria, } \\
\text { muscular and serosa }\end{array}$ & +++ & + \\
\hline $\begin{array}{l}\text { Bovine } 4863 \\
\quad 24498\end{array}$ & $\begin{array}{l}+ \text { sanguineous } \\
\text { and lymphatic }\end{array}$ & $\begin{array}{l}+ \text { sanguineous } \\
\text { and lymphatic }\end{array}$ & $(+)$ & ++ & $(+)$ & $\begin{array}{c}++(+) \\
\text { lamina propria } \\
\text { and muscular }\end{array}$ & - & - \\
\hline $\begin{array}{l}\text { Bovine } 4864 \\
\quad 24581\end{array}$ & $\begin{array}{l}++ \text { sanguineous } \\
\text { and lymphatic }\end{array}$ & $\begin{array}{l}(+) \text { sanguineous } \\
\text { and lymphatic }\end{array}$ & ++ & + & $+(+)$ & $\begin{array}{c}+++ \\
\text { lamina propria, } \\
\text { muscular and serosa }\end{array}$ & + & $?$ \\
\hline $\begin{array}{l}\text { Bovine } 4865 \\
\quad 24582\end{array}$ & + & $(+)$ & - & ++ & +++ & $\begin{array}{c}++ \\
\text { muscular }\end{array}$ & $\begin{array}{c}+ \\
\text { multifocal }\end{array}$ & - \\
\hline 18207 & $(+)$ & $+(+)$ & - & + & $(+)$ & $\begin{array}{c}+(+) \\
\text { lamina propria }\end{array}$ & - & - \\
\hline $\begin{array}{c}\text { Bovine } 2145 \\
16759-60\end{array}$ & $(+)$ & - & - & $(+)$ & $+(+)$ & $\begin{array}{c}++ \\
\text { muscular }\end{array}$ & - & - \\
\hline 20667 & ++ & ++ & $(+)$ & - & $(+)$ & $\begin{array}{c}(+) \\
\text { lamina propria }\end{array}$ & - & - \\
\hline 20289 & $+(+)$ & $(+)$ & - & $(+)$ & $(+)$ & $\begin{array}{c}(+) \\
\text { muscular }\end{array}$ & - & - \\
\hline 20896 & $+(+)$ & - & - & + & $++(+)$ & $\begin{array}{c}++ \\
\text { muscular }\end{array}$ & $+(+)$ & - \\
\hline 28231 & ++ & $(+)$ & ++ & - & ++ & $\begin{array}{c}++ \\
\text { muscular } \\
\text { and serosa }\end{array}$ & + & - \\
\hline 29056 & $+(+)$ & $(+)$ & $(+)$ & ++ & +++ & $\begin{array}{c}\quad++ \\
\text { muscular } \\
\text { and serosa }\end{array}$ & $(+)$ & - \\
\hline $\begin{array}{l}866 \\
\text { Paraná }\end{array}$ & $(+)$ & $(+)$ & $(+)$ & - & ++ & $\begin{array}{c}++ \\
\text { muscular } \\
\text { and serosa }\end{array}$ & - & - \\
\hline $\begin{array}{l}920 \\
\text { Paraná }\end{array}$ & ++ & $(+)$ & $(+)$ & +++ & ++ & $\begin{array}{c}\quad++ \\
\text { muscular } \\
\text { and serosa }\end{array}$ & - & - \\
\hline 29279 & $+(+)$ & $+(+)$ & $(+)$ & ++ & $(+)$ & $\begin{array}{c}(+) \\
\text { lamina propria }\end{array}$ & - & - \\
\hline 28196 & $+(+)$ & $+(+)$ & $(+)$ & ++ & ++ & $\begin{array}{c}+(+) \\
\text { lamina propria } \\
\text { and muscular }\end{array}$ & + & - \\
\hline Vn-65-77 & + & + & + & - & - & $\begin{array}{c}(+) \\
\text { lamina propria }\end{array}$ & - & - \\
\hline V-214-83 & $(+)$ & $+(+)$ & $(+)$ & $+(+)$ & $+(+)$ & $\begin{array}{c}(+) \\
\text { lamina propria }\end{array}$ & - & - \\
\hline V-328-84 & + & + & $(+)$ & + & $(+)$ & $\begin{array}{c}(+) \\
\text { lamina propria } \\
\text { and muscular }\end{array}$ & + & - \\
\hline V-65-87 & ++ & $(+)$ & ++ & - & - & $\begin{array}{c}(+) \\
\text { lamina propria }\end{array}$ & - & - \\
\hline V-211-87 & $(+)$ & - & - & $+(+)$ & $(+)$ & $\begin{array}{c}(+) \\
\text { lamina propria }\end{array}$ & - & - \\
\hline V-563-89 & + & $(+)$ & $(+)$ & - & - & $\begin{array}{c}(+) \\
\text { lamina propria }\end{array}$ & - & - \\
\hline V-36-90 & $(+)$ & $(+)$ & $(+)$ & _- & $(+)$ & $\begin{array}{c}+++ \\
\text { lamina propria, } \\
\text { muscular and serosa }\end{array}$ & - & - \\
\hline Vn-4-94 & $(+)$ & - & - & $(+)$ & $(+)$ & $\begin{array}{c}(+) \\
\text { lamina propria }\end{array}$ & - & - \\
\hline V-265-90 & ++ & $+(+)$ & ++ & ++ & ++ & $\begin{array}{c}+++ \\
\text { lamina propria, } \\
\text { muscular and serosa }\end{array}$ & + & - \\
\hline V-266-90 & ++ & $+(+)$ & ++ & $(+)$ & ++ & $\begin{array}{c}+++ \\
\text { lamina propria, } \\
\text { muscular and serosa }\end{array}$ & + & - \\
\hline
\end{tabular}


Table 4. Non-neoplastic lesions associated with BEH in Brazil (Continuation)

\begin{tabular}{|c|c|c|c|c|c|c|c|c|}
\hline Protocol & $\begin{array}{c}\text { Vascular } \\
\text { proliferation }\end{array}$ & $\begin{array}{c}\text { Vascular } \\
\text { ectasy }\end{array}$ & Hemorrhage & $\begin{array}{l}\text { Lymphocytic } \\
\text { focus }\end{array}$ & $\begin{array}{c}\text { Diffuse lymphocytic } \\
\text { infiltration }\end{array}$ & Fibrosis & $\begin{array}{l}\text { Myxoid } \\
\text { stroma }\end{array}$ & $\begin{array}{l}\text { Inflammatory } \\
\text { pseudotumor }\end{array}$ \\
\hline V-269-90 & $++^{\mathrm{a}}$ & $(+)$ & - & $(+)$ & ++ & $\begin{array}{c}++ \\
\text { lamina propria, } \\
\text { muscular and serosa }\end{array}$ & - & - \\
\hline V-270-90 & ++ & - & - & - & $+(+)$ & $\begin{array}{c}+++ \\
\text { lamina propria, } \\
\text { muscular and serosa }\end{array}$ & - & - \\
\hline V-271-90 & + & - & - & ++ & ++ & $\begin{array}{c}++ \\
\text { lamina propria, } \\
\text { muscular and serosa }\end{array}$ & + & - \\
\hline V-272-90 & + & - & - & ++ & ++ & $\begin{array}{c}++ \\
\text { lamina propria, } \\
\text { muscular and serosa }\end{array}$ & - & - \\
\hline V-273-90 & $(+)$ & - & - & - & $(+)$ & $\begin{array}{c}+++ \\
\text { lamina propria, } \\
\text { muscular and serosa }\end{array}$ & - & - \\
\hline V-274-90 & $++(+)$ & + & + & $+(+)$ & $+(+)$ & $\begin{array}{c}++(+) \\
\text { lamina propria, } \\
\text { muscular and serosa }\end{array}$ & - & - \\
\hline V-275-90 & $+(+)$ & $(+)$ & ++ & + & ++ & $\begin{array}{c}++ \\
\text { lamina propria } \\
\text { and muscular }\end{array}$ & - & - \\
\hline V-276-90 & ++ & ++ & $+(+)$ & $(+)$ & ++ & $\begin{array}{c}+ \\
\text { lamina propria } \\
\text { and muscular }\end{array}$ & - & - \\
\hline V-277-90 & + & - & - & - & $+(+)$ & $\begin{array}{c}+ \\
\text { lamina propria } \\
\text { and muscular }\end{array}$ & - & - \\
\hline V278-90 & ++ & $(+)$ & - & $(+)$ & $+(+)$ & $\begin{array}{c}+ \\
+ \\
\text { lamina propria } \\
\text { and muscular }\end{array}$ & - & - \\
\hline V-448-90 & - & - & + & - & + & $\begin{array}{c}+ \\
\text { lamina propria, } \\
\text { muscular and serosa }\end{array}$ & $(+)$ & - \\
\hline 24762 & $+(+)$ & - & - & $(+)$ & - & $\begin{array}{c}(+) \\
\text { lamina propria }\end{array}$ & - & - \\
\hline 24765 & ++ & $(+)$ & $(+)$ & - & + & $\begin{array}{c}(+) \\
\text { lamina propria }\end{array}$ & - & - \\
\hline 24796 & ++ & $(+)$ & $+(+)$ & $(+)$ & $(+)$ & $\begin{array}{c}+++ \\
\text { lamina propria, sero- } \\
\text { sa and muscular }\end{array}$ & - & - \\
\hline V-234-91 & $+(+)$ & + & _ & $+(+)$ & $(+)$ & _ & - & - \\
\hline $\begin{array}{l}\text { Bovine } 823 \\
13694,13775-79, \\
17806\end{array}$ & $+(+)$ & $(+)$ & - & $+(+)$ & + & $\begin{array}{c}+ \\
\text { lamina propria }\end{array}$ & - & - \\
\hline $\begin{array}{c}\text { Bovine } 874 \\
14768-70\end{array}$ & $+(+)$ & $(+)$ & - & $(+)$ & $(+)$ & $\stackrel{+}{+}$ & - & - \\
\hline $\begin{array}{c}\text { Bovine } 961 \\
15302-305 \\
17807\end{array}$ & $+(+)$ & $(+)$ & ++ & + & $(+)$ & $\begin{array}{c}+(+) \\
\text { lamina propria }\end{array}$ & - & - \\
\hline $\begin{array}{c}\text { Bovine } 2377 \\
18238-42\end{array}$ & $+(+)$ & _ & - & +++ & ++ & $\begin{array}{c}++ \\
\text { lamina propria }\end{array}$ & $+(+)$ & - \\
\hline $\begin{array}{c}\text { Bovine } 2379 \\
18245-47\end{array}$ & $+(+)$ & - & ++ & ++ & $+(+)$ & $\begin{array}{c}++ \\
\text { lamina propria }\end{array}$ & ++ & - \\
\hline $\begin{array}{c}\text { Bovine } 2380 \\
18248-51\end{array}$ & $+(+)$ & $+(+)$ & - & $+(+)$ & ++ & $\begin{array}{c}+(+) \\
\text { lamina propria }\end{array}$ & + & - \\
\hline $\begin{array}{c}\text { Bovine } 2381 \\
18252-53\end{array}$ & + & + & + & ++ & $+(+)$ & $\begin{array}{c}+(+) \\
\text { lamina propria }\end{array}$ & + & - \\
\hline $\begin{array}{l}\text { Bovine } 2396 \\
18394-18301\end{array}$ & $(+)$ & - & - & ++ & - & $\begin{array}{c}(+) \\
\text { lamina propria }\end{array}$ & - & - \\
\hline $\begin{array}{c}\text { Bovine } 2188 \\
17422-24 \\
17808\end{array}$ & + & - & $(+)$ & + & - & $\begin{array}{c}++ \\
\text { lamina propria }\end{array}$ & - & - \\
\hline $\begin{array}{c}\text { Bovine } 2286 \\
17863-67\end{array}$ & $\begin{array}{r}+(+) \\
\text { atypic }\end{array}$ & $\begin{array}{c}(+) \\
\text { thrombosis }\end{array}$ & $(+)$ & $(+)$ & + & $\begin{array}{c}(+) \\
\text { lamina propria }\end{array}$ & - & - \\
\hline
\end{tabular}


Table 4. Non-neoplastic lesions associated with BEH in Brazil (Continuation)

\begin{tabular}{|c|c|c|c|c|c|c|c|c|}
\hline Protocol & $\begin{array}{c}\text { Vascular } \\
\text { proliferation }\end{array}$ & $\begin{array}{c}\text { Vascular } \\
\text { ectasy }\end{array}$ & Hemorrhage & $\begin{array}{l}\text { Lymphocytic } \\
\text { focus }\end{array}$ & $\begin{array}{c}\text { Diffuse lymphocytic } \\
\text { infiltration }\end{array}$ & Fibrosis & $\begin{array}{r}\text { Myxoid } \\
\text { stroma }\end{array}$ & $\begin{array}{l}\text { Inflammatory } \\
\text { pseudotumor }\end{array}$ \\
\hline $\begin{array}{c}\text { Bovine } 2291 \\
17898-900 \\
17911\end{array}$ & $(+)$ & - & - & - & - & $\begin{array}{c}(+) \\
\text { lamina propria }\end{array}$ & - & - \\
\hline $\begin{array}{c}\text { Bovine } 2303 \\
17907-910\end{array}$ & $+(+)$ & - & - & - & $(+)$ & $\begin{array}{c}+ \\
\text { lamina propria }\end{array}$ & - & - \\
\hline $\begin{array}{c}\text { Bovine } 2285 \\
17857-62\end{array}$ & $(+)$ & - & - & $+(+)$ & - & - & - & - \\
\hline $\begin{array}{c}\text { Bovine } 2287 \\
17868-70\end{array}$ & $(+)$ & - & - & + & + & $\begin{array}{c}+(+) \\
\text { lamina propria }\end{array}$ & - & - \\
\hline $\begin{array}{c}\text { Bovine } 2371 \\
18231-33\end{array}$ & $(+)$ & - & - & - & $(+)$ & $\begin{array}{c}(+) \\
\text { lamina propria }\end{array}$ & - & - \\
\hline $\begin{array}{c}\text { Bovine } 2374 \\
18234-36\end{array}$ & $(+)$ & - & - & $(+)$ & $(+)$ & $\begin{array}{c}(+) \\
\text { lamina propria }\end{array}$ & - & - \\
\hline $\begin{array}{c}\text { Bovine } 2376 \\
18237\end{array}$ & $(+)$ & - & - & $(+)$ & $(+)$ & $\begin{array}{c}(+) \\
\text { lamina propria }\end{array}$ & - & - \\
\hline $\begin{array}{c}\text { Bovine2382 } \\
18254-56\end{array}$ & $(+)$ & - & - & - & $(+)$ & - & - & - \\
\hline $\begin{array}{c}\text { Bovine } 2385 \\
18257\end{array}$ & - & - & - & $(+)$ & - & - & - & - \\
\hline
\end{tabular}

a - no lesion, $(+)$ very low, + low, $+(+)$ low to moderate, ++ moderate, $++(+)$ moderate to high, +++ high-grade, $?$ uncertain lesion .

lical portion of the abdominal wall (Murphy et al. 1994). In fact, embryo-genesis makes it easier to understand the reason for the presence of the neoplastic and metaplastic alterations identical to renal and intestinal tissues in the bladder of cattle and human beings. It would be interesting to verify the exact correlation between the different portions of the bladder (in agreement with the embryogenesis) and the frequency of the various types of neoplasm. In this study that aspect could not be considered because the whole bladder was only available in a few cases. Most of the received fragments were collected at random from several parts of the bladder, mainly from areas that presented macroscopic alterations; therefore areas of the bladder without evident macroscopic lesions, but with possible significant microscopic alterations, were excluded from this study. Even so, why one and the same carcinogenic agent can give origin to different neoplasms in the same animal, is still a mystery. Possibly there is a relationship between the period during which the plant is ingested and the amount of carcinogens contained in the plant in each outbreak. Pamukçu et al. (1967) mentions the largest frequency of transitional carcinomas in bovines that survived for longer time.

Regarding the incidence of the main neoplasms found in cattle with BEH in our study, it is not easy to make exact comparisons with the data found in the literature. First, because few authors mention the frequency of the different histological types. This comparison is also very difficult to make because, in many cases, the animals present two or more types of neoplasm. Another problem for the exact determination of the frequency of these neoplasms is the possible variation in the nomenclature used by different pathologists. This has also been mentioned by Murphy et al. (1994) in relation to bladder neoplasms in man. Lesions interpreted as "severe dysplasia" by some authors, were considered as neoplastic by others.

In a similar way, the methodology and/or the criteria used in the evaluation, also has influence on classification. For example in their studies Pamukçu et al. (1976) and McKenzie (1978) apparently included only animals with true neoplasms. In our survey, we also included animals with BEH that presented only non- neoplastic alterations. These were $22 \%$ of the total.

At this point we think it opportune to mention that $\mathrm{BEH}$ can also be caused by inflammatory and vascular alterations, without the presence of neoplasms (Rosenberger \& Heeschen 1960, Muller et al. 1975, Nielsen \& Moulton 1990, Tokarnia et al. 2000). For this reason we preferred to include cases in which neoplasms were not present. This should be taken into account in the interpretation of the results.

Nevertheless, some of the data found by us are more or less consistent with those in the literature. For instance, we found $44 \%$ of carcinomas of transition cells (CCT), a number close to the $32.5 \%$ of CCT observed in cattle and buffalos with BEH in Turkey (Pamukçu et al. 1976). Natural occurring transitional carcinomas, also were observed more frequently in the bladder of sheep (McCrea \& Head 1981). Additionally we found $42.3 \%$ carcinomas "in situ". Similar proportions were also verified regarding transitional cell papillomas of (PCT), $17 \%$ and $16.9 \%$ in the studies of Pamukçu (1974) and in our series, respectively. Though, in another work, Pamukcu et al. (1976) verified $24 \%$ of PCT. In these studies adenomas were rare (3.5\%); in our series they amounted to $10.1 \%$ of the tumors. But the number of epidermoid carcinomas (16.9\%) observed by us was higher, and that of adenocarcinomas (8.4\%) was slightly lower (excluding the mesonephroid adenocarcinoma), when compared with those reported by Pamukçu et al. (1976), which were $10.7 \%$ and $13.6 \%$, respectively. 
Table 5. Incidence of lesions asociated with BEH in Brazil

\begin{tabular}{|c|c|c|}
\hline Bladder lesions & $\begin{array}{c}\text { Number of } \\
\text { affected animals }\end{array}$ & Incidence \\
\hline Carcinoma in situ & 25 & $42,3 \%$ \\
\hline Transitional carcinoma low grade & 1 & $1,6 \%$ \\
\hline Transitional carcinoma low grade with intestinal differentiation & 1 & $1,6 \%$ \\
\hline Transitional carcinoma low grade with pseudoglandular differentiation & 1 & $1,6 \%$ \\
\hline Transitional carcinoma moderate grade with squamous, mesonephroid and pseudoglandular differentiation & 1 & $1,6 \%$ \\
\hline Transitional carcinoma high grade & 1 & $1,6 \%$ \\
\hline Transitional carcinoma high grade with pseudosarcomatous stroma & 2 & $3,3 \%$ \\
\hline Transitional carcinoma high grade with pseudoglandular differentiation & 2 & $3,3 \%$ \\
\hline Transitional carcinoma high grade with pseudoglandular differentiation and pseudosarcomatous stroma & 2 & $3,3 \%$ \\
\hline Transitional carcinoma high grade with intestinal, mesonephroid and pseudoglandular differentiation & 4 & $6,7 \%$ \\
\hline Transitional carcinoma high grade with squamous, mesonephroid and intestinal differentiation & 1 & $1,6 \%$ \\
\hline Transitional carcinoma high grade with squamous, pseudoglandular and chromophobe cell differentiation & 1 & $1,6 \%$ \\
\hline Transitional carcinoma high grade with intestinal and pseudoglandular differentiation & 1 & $1,6 \%$ \\
\hline Transitional carcinoma high grade with squamous and intestinal and pseudosarcomatous stroma & 1 & $1,6 \%$ \\
\hline Transitional carcinoma high grade with squamous and pseudoglandular differentiation & 5 & $8,4 \%$ \\
\hline Transitional carcinoma high grade with mesonephroid differentiation & 1 & $1,6 \%$ \\
\hline Transitional carcinoma high grade with squamous, mesonephroid and pseudoglandular & 1 & $1,6 \%$ \\
\hline Squamous carcinoma & 4 & $6,7 \%$ \\
\hline Squamous carcinoma with pseudoglandular differentiation & 6 & $10,1 \%$ \\
\hline Trabecular carcinoma with Paneth cells differentiation & 1 & $1,6 \%$ \\
\hline Trabecular carcinoma with squamous differentiation & 1 & $1,6 \%$ \\
\hline Poorly differentiated carcinoma & 5 & $8,4 \%$ \\
\hline Poorly differentiated carcinoma with pseudoglandular differentiation & 2 & $3,3 \%$ \\
\hline Adenocarcinoma & 1 & $1,6 \%$ \\
\hline Adenocarcinoma with intestinal differentiation & 3 & $5,0 \%$ \\
\hline Adenocarcinoma with intestinal and Paneth cells differentiation & 1 & $1,6 \%$ \\
\hline Mesonephroid adenocarcinoma & 3 & $5,0 \%$ \\
\hline Mesonephroid adenocarcinoma with chromophobe cell differentiation & 1 & $1,6 \%$ \\
\hline Carcinoma (transitional) with spindle cell stroma & 1 & $1,6 \%$ \\
\hline Carcinoma (squamous) with spindle cell stroma & 1 & $1,6 \%$ \\
\hline Signet ring cell carcinoma & 1 & $1,6 \%$ \\
\hline Plasmacytoid carcinoma & 1 & $1,6 \%$ \\
\hline Chromophobe cell carcinoma & 1 & $1,6 \%$ \\
\hline Sarcomatoid carcinoma? & $1 ?$ & $1,6 \%$ \\
\hline Sarcomatoid carcinoma with syncytiotrophoblastic cells? ${ }^{a}$ & $1 ?$ & $1,6 \%$ \\
\hline Sarcomatoid carcinoma or carcinosarcoma? & (Bovine 4864)? & $?$ \\
\hline Hemangiosarcoma & 14 & $23,7 \%$ \\
\hline Hemangiosarcoma with syncytiotrophoblastic cells & 1 & $1,6 \%$ \\
\hline Transitional papilloma & 10 & $16,9 \%$ \\
\hline Transitional papilloma with mesonephroid differentiation & 2 & $3,3 \%$ \\
\hline Transitional adenoma & 5 & $8,4 \%$ \\
\hline Transitional adenoma with intestinal differentiation & 1 & $1,6 \%$ \\
\hline Mesonephroid adenoma & 2 & $3,3 \%$ \\
\hline Capillary hemangioma & 11 & $18,6 \%$ \\
\hline Cavernous hemangioma & 12 & $20,3 \%$ \\
\hline Venous hemangioma & 12 & $20,3 \%$ \\
\hline Myxoma & 2 & $3,3 \%$ \\
\hline Urothelial hyperplasia & 12 & $20,3 \%$ \\
\hline Urothelial dysplasia grade I, II and III & 32 & $54,2 \%$ \\
\hline Intestinal metaplasia & 6 & $10,1 \%$ \\
\hline Mesonephroid metaplasia & 9 & $15,2 \%$ \\
\hline Squamous metaplasia & 1 & $1,6 \%$ \\
\hline Chromophobe cell metaplasia & 4 & $6,7 \%$ \\
\hline Brunn nests & 41 & $69,4 \%$ \\
\hline Cystitis cystica & 24 & $40,6 \%$ \\
\hline Cystitis glandularis & 6 & $10,1 \%$ \\
\hline Polypoid proliferation & 36 & $61,0 \%$ \\
\hline Micropolypoid proliferation & 17 & $28,8 \%$ \\
\hline Intraepithelial cysts & 26 & $44,0 \%$ \\
\hline Vascular proliferation & 58 & $98,3 \%$ \\
\hline Vascular ectasy & 35 & $59,3 \%$ \\
\hline Hemorrhage & 29 & $49,1 \%$ \\
\hline Lymphocytic focus & 43 & $72,8 \%$ \\
\hline Diffuse lymphocytic infiltration & 50 & $84,7 \%$ \\
\hline Fibrosis & 55 & $93,2 \%$ \\
\hline Myxoid stroma & 16 & $27,1 \%$ \\
\hline Inflammatory pseudotumor? & + (Bovine 4864)? & $?$ \\
\hline
\end{tabular}

\footnotetext{
a ? Uncertain lesion.
} 
Transitional epithelium neoplasms (more or less differentiated) are frequent in animals (Pamukcu 1974, Pamukcu et al. 1976, Nielsen \& Moulton 1990) and in man (Murphy et al. 1994, Ordónez \& Rosai 1996). However, there are some differentiations described as rare or infrequent for humans (Murphy et al. 1994, Ordónez \& Rosai 1996) not mentioned in the veterinary literature that occurred with more or less significant prevalence in our cases of BEH. For example, neoplastic and metaplastic processes with nephrogenic (mesonephroid) characteristics can be mentioned. Beside this we verified intermediate differentiation between urothelial hyperplasia, metaplasia, nephrogenic adenoma and adenocarcinoma. Other authors, however, do not mention or do not believe in the occurrence of nephrogenic adenocarcinomas even in man (Murphy et al. 1994).

Trabecular carcinoma with Paneth cell differentiation, mesonephroid adenoma, mesonephroid adenocarcinoma, "signet ring"cell carcinoma, plasmocytoid carcinoma, chromophobe cell carcinoma and nested type of transitional carcinoma, although rare in our study, have not yet been described in the bladder of cattle with $\mathrm{BEH}$.

Regarding mesenchymal tumors, we observed a high number of vascular neoplasias $(84.7 \%$, being $25.4 \%$ hemangiosarcomas and $59.3 \%$ hemangiomas), a fact also observed in Australia (84.1\%, McKenzie 1978). In cattle with BEH in Turkey, these indexes were lower (56.1\% - Pamuku et al. 1976). In Japan angiomas $(87.8 \%)$ were more frequently observed (Maeda 1978).

The coexistence of tumors with elements of epithelial and mesenchymal origin, as well as the concomitance of two or more types of tumors of the same origin, in only one animal, also complicates the attempt to determine the frequency of the neoplasms which occur in BEH. Pamukcu et al. (1976) verified the simultaneous occurrence of mesenchymal and epithelial tumors in $54 \%$ of cases of $\mathrm{BEH}$, while we verified this in 30.5\% and McKenzie (1978) in 15.7\%. Maeda (1978) observed two or more tumor types in $54.5 \%$ of the bovines. Part of this discrepancy may be due to the criteria of classification or the methodology used. For instance, we made the computation on the total of the animals with BEH (59), however 13 of them (22\%) presented only non-neoplastic alterations. If the computation would be made only on the animals with neoplasias, as apparently used by the authors mentioned above, the percentage in our study would rise to $39.1 \%$.

In the cases of BEH with pure epithelial neoplasms (including here the cases with two or more epithelial neoplasms) we found a percentage of $33.8 \%$ (or $42.5 \%$, leaving out of the calculation the non-neoplastic changes), against 35\% (Pamukcu et al. 1976) and 15.7\% (McKenzie 1978).

In respect to the mesenchymal tumors, a percentage of 9\% (Pamukcu et al. 1976) and 15.2\% (our study) again contrasts with the $68.4 \%$ found by McKenzie (1978). Although it is just a hypothesis, it may be that those discrepancies are due to the fact that the outbreaks of BEH described in that last paper were due to the ingestion of Pteridium esculentum (3 properties) or Cheilantes sieberi (4 properties), that could contain carcinogens with different activity/intensity from that of $P$. aquilinum.

The biological behavior of the alterations that occur in the bladder of animals with BEH is difficult to understand. For instance: neoplasias with severe anaplasia and evident infiltrative potentiality (infiltration in the detrusor muscle and even in the serosa), with vascular invasion, rarely are capable of metastasizing into regional lymph nodes and other organs. In man, metastases of transitional carcinoma usually are associated with tumorous invasion into the muscular wall and, have even been observed in regional lymph nodes of $14 \%$ of the patients with superficial neoplasias (Murphy et al. 1994). This point had already been mentioned by Tokarnia et al. (2000). The most logical explanation is that the local immunological reaction would impede the spread of the neoplasia. In fact, as reported by other authors (Rosenberger \& Heeschen 1960, Döbereiner et al. 1967, Tokarnia et al. 1969, Smith \& Beatson 1970), we also observed inflammatory infiltration, predominantly lymphocytic, diffuse or focal, with variable degrees of intensity. This inflammation accompanied several types of benign and maligne tumors, however it was more frequent and intense in more aggressive neoplasias. On the other hand, diffuse lymphocytic infiltration and formation of lymphoid foci also occurred in bladders without neoplastic processes. Therefore these findings do not allow a simple correlation between this type of inflammation and some metaplastic or specific neoplastic alterations or with a specific protective alteration against tecidual infiltration of the neoplasia or metastases. Still, we registered cases with unequivocal presence of neoplastic cells in vessels, without signs of distant metastases. The elucidation of the cause(s) of this "barrier against metastases" and their relationship with the chemical carcinogenesis induced by the ptaquiloside may be of interest in future studies that aim to combat cancer in man and animals.

Eosinophils were also seen in neoplasms, mainly squamous cell carcinomas or areas of squamous differentiation and their presence is correlated with the antigenicity of the keratin present in these tumors (Murphy et al. 1994). In one case, we observed eosinophilic infiltration of an hemangioma and also under the urothelium together with lymphocytic infiltration (29279). We can not explain the presence of the eosinophils in this case.

Regarding the nomenclature and classification of general pathology, the term metaplasia is used for malignant tumors (Nielsen \& Moulton 1990, Ordónez \& Rosai 1996). However as it defines the transition of a morphologically normal tissue into another, it does not seem logical to use it for neoplastic proliferations. The word differentiation seems to us more appropriate. On the other hand, small variations between the different classifications in nomenclature sometimes just reflect a preference for one or other term. For instance, the alteration denominated carcinoma "in situ" by us is classified by some authors as dysplasia degree IV. We opted for the first designation, in function of the marked anaplasia present in these alterations. We also preferred to use the term transitional or squamous carcinoma with areas of pseudo-glan- 
dular differentiation to the one of carcinoma of transitional cells with lumen similar to the gland, used by AFIP (Murphy et al. 1994), because we observed this alteration in transitional and squamous carcinomas, while Murphy et al. (1994) mention this only in transitional carcinomas, in which the "glandular" spaces are surrounded by epithelium with pseudo stratified appearance and the superficial cells differentiate into transitional epithelium. In our cases, the "gland" structures are formed following the necrosis of transitional and squamous tumorous cells.

Beside the intestinal metaplasia observed in part of the Brunn nests, that characterizes the so called Cystitis glandularis or intestinal metaplasia, we also verified, in a small number of cases, squamous, mesonephroid and mesonephroid type cell chromophobe metaplasia, in these structures, lesions not yet described in veterinary medicine. Still regarding metaplastic processes we also found foci of intestinal metaplasia, close to carcinomas, in areas of transitional hyperplastic epithelium (Case 24581). There were also coexistence or intermediate phases between several types of metaplasia. An intermediate phase was observed between intestinal metaplasia and mesonephroid proliferation (Case 24496), characterized by a bistratified metaplastic process, mostly with basal polar nuclei, cylindrical or basal nuclei perpendicular to each other, layer for layer. In several cases, the dysplastic changes occurred on different sites, at the same time. Beside this, we verified that parts of the carcinomas "in situ" were associated with the formation of multicentric epithelial neoplasms. These data corroborate with the statement of Nielsen \& Moulton (1990) that the occurrence of the lesions is associated with the exhibition of different areas to the carcinogens.

We noted that part of the transitional carcinomas with spindle cell stroma and with pseudoglandular differentiation had a marked similarity with carcinomas of the uterus of cows. We had difficulty in the differentiation between sarcomatoid carcinoma, carcinosarcoma and carcinoma with spindle cell stroma, since the fusiform portion of these neoplasms closely resemble each other. The exact determination, in our opinion, is only possible through immunohistochemistry and/or electron microscopy, which can be accomplished in future studies.

In two cases, we found contiguous neoplasms, the socalled "collision of tumors"; in the first case (24581) a neoplasm of more invasive growth (transitional carcinoma) invaded the other (cavernous hemangioma) of more expansible growth. In the other case (V-274-90) a squamous carcinoma infiltrating a hemangiosarcoma was observed.

A well differentiated proliferation of blood vessels in the propria, diffuse or localized to greater or smaller degree, was observed in all animals. In some animals this process was accompanied by dysplasia and hyperplasia of vessels of the stroma and vessels of the bladder muscles, besides metaplastic alterations of the connective tissue surrounding those vessels, into mixoid connective tissue (cases 24582 and 28231).
Other processes were also found inside some vessels, such as the proliferation of endothelial cells of the intima of arteries, forming small "papillae" in the vascular lumen, or even of the media, with marked thickening of the vascular muscle layer (cases 24582 and V-276-90). Nielsen \& Moulton (1990) refer to the occurrence of obliterant endarteritis and detachment of the vascular endothelium in the bladder of cattle affected by BEH. Ordónez \& Rosai (1994) described similar lesions in the bladder of humans submitted to radiotherapy.

\section{REFERENCES}

Döbereiner J., Tokarnia C.H. \& Canella C.F.C. 1967. Ocorrência da hematúria enzoótica e de carcinomas epidermóides no trato digestivo superior em bovinos no Brasil. Pesq. Agropec. Bras., Sér. Vet., 2:489-504.

Evans W.C., Evans E.T.R. \& Hughes L.E. 1954. Studies on bracken poisoning in cattle - Part I. Brit. Vet. J. 110(8):295-306.

Evans I.A., Humphreys D.J., Goulden L., Thomas A.J. \& Evans W.C. 1963. Effects of bracken rhizomes on the pig. J. Comp. Pathol. Therap. 73(3):229-243.

Evans W.C. 1976. Bracken thiaminase-mediated neurotoxic syndromes. Bot. J. Linnean Soc. 73:113-131.

Heeschen W. 1959. Die Haematuria vesicalis bovis chronica. Dtsch. Tierärztl. Wschr. 66(22):622-626, (24):678-682.

Hirono I., Aiso S.,Yamaji T., Mori H., Yamada K., Niwa H., Ojika M., Wakamatsu K., Kigoshi H., Niiyama K \& Uosaki Y. 1984. Carcinogenicity in rats of ptaquiloside isolated from bracken. Gann. 75:833-836.

Maeda T. 1978. Studies on chronic bovine hematuria vesicalis due to tumours. IV. Histopathology of urocystic tumors. Bull. Agric., Tottori Univ., 31:7883.

McCrea C.T. \& Head K.W. 1981. Sheep tumours in Northeast Yorkshire. II. Experimental production of tumours. Brit. Vet. J. 137:21-30.

McKenzie R.A. 1978. Bovine enzootic haematuria in Queensland. Aust. Vet. J. 54:61-64.

Muller S.B.K., Madureira F.R., Alencar Filho R.A., Ribeiro L.O.C. \& Souza J.A. 1975. Tentativa de reprodução experimental da hematúria enzoótica em bovinos pela administração de samambaia. Arqs Inst. Biológico, São Paulo, 42:203-212.

Murphy W.M, Beckwith J.B. \& Farrow G.M. 1994. Atlas of Tumor Pathology: Tumors of the Kidney, Bladder, and Related Urinary Structures. Third Series. Fasc. 11. AFIP Washington, DC. 326p.

Naftalin J.M. \& Cushnie G.H. 1954. Pathology of bracken poisoning in cattle. J. Comp. Pathol. Therap. 64:54-74.

Nielsen S.W. \& Moulton J.E. 1990. Tumors of the Urinary System, p.458-478. In: Tumors in Domestic Animals. 3rd ed. University of California Press, Berkeley, California. 672p

Ordónez N.G. \& Rosai J. 1996. Urinary tract: Kidney, renal pelvis, and ureter, bladder and male urethra, p.1059-1220. In: Rosai J. (ed.) Ackerman's Surgical Pathology. Vol. 1. $8^{\text {th }}$ ed. Mosby, St. Louis.

Pamukçu A.M., Göksoy S.K. \& Price J.M. 1967. Urinary bladder neoplasms induced by feeding bracken fern (Pteris aquilina) to cows. Cancer Res. 27(1):917-924.

Pamukçu A.M. 1974. Tumors of the Urinary Bladder. Bull. Wld Hlth Org., Genève, 50(12):43-52.

Pamukçu A.M., Price J.M. \& Bryan G.T. 1976. Naturally occurring and brackenfern-induced bovine urinary bladder tumors. Vet. Path. 13:110-122.

Pirie H.M. 1973. Unusual occurrence of squamous carcinoma of the upper alimentary tract in cattle in Britain. Res. Vet. Sci. 15:135-138.

Rosenberger G. \& Heeschen W. 1960. Adlerfarn (Pteris aquilina) - die Ursache 
des sog. Stallrotes der Rinder (Haematuria vesicalis bovis chronica). Dtsch. Tierärztl. Wschr. 67(8):201-208.

Rosenberger G. 1965. Längere Aufnahme von Adlerfarn (Pteris aquilina) - die Ursache der chronischen vesikalen Haematurie des Rindes. Wiener Tierärztl. Mschr. 52(5):415-421.

Simpson B.H. 1972. The geographic distribuition of carcinomas of the small intestine in New Zealand sheep. N.Z. Vet. J. 20(3):24-28.

Sippel L. 1952. Bracken fern poisoning. J. Am. Vet. Med. Assoc. 121:9-13.
Smith B.L. \& Beatson N.S. 1970. Bovine enzootic haematuria in New Zealand. N. Z. Vet. J. 18(6):115-120

Tokarnia C.H., Döbereiner J. \& Canella C.F.C. 1969. Ocorrência da hematúria enzoótica e de carcinomas epidermóides no trato digestivo superior em bovinos no Brasil. II. Estudos complementares. Pesq. Agropec. Bras., Sér. Vet., 4:209-224.

Tokarnia C.H., Döbereiner J. \& Peixoto P.V. 2000. Plantas Tóxicas do Brasil. Editora Helianthus, Rio de Janeiro. 320p. 
O arquivo disponível sofreu correções conforme ERRATA publicada no Volume 23 Número 3 da revista. 